\title{
The Hedgehog inhibitor cyclopamine antagonizes chemoresistance of breast cancer cells
}

This article was published in the following Dove Press journal:

OncoTargets and Therapy

II November 2013

Number of times this article has been viewed

\author{
Feng Chai' \\ Jiangang Zhou' \\ Cheng Chen' \\ Song $\mathrm{Xie}^{2}$ \\ Xiao Chen' \\ Ping $\mathrm{Su}^{3}$ \\ Jun $\mathrm{Shi}^{3}$
}

'Oncology Department, ${ }^{2}$ General Surgery Department, ${ }^{3} \mathrm{Hematology}$ Department, Zhejiang Xiaoshan Hospital, Hangzhou, People's Republic of China
Correspondence: Jun Shi Hematology Department, Zhejiang Xiaoshan Hospital, 728 Yu Cai Bei Road, Hangzhou, Zhejiang 3II200,

People's Republic of China Email zhejiang_xiaoshan@I63.com

\begin{abstract}
Chemoresistance of cancer cells has been a severe problem in multiple types of cancers. One possibility is to combine different drugs with chemotherapy for improved efficacy. Cyclopamine blocks Hedgehog signaling by antagonizing Smo function, which induces tumor apoptosis. Here, we show that the combined use of cyclopamine and paclitaxel (chemotherapy drugs) was able to induce breast cancer cell apoptosis both in vivo and in vitro. The results suggest that Hedgehog signaling is a prospective drug target for chemoresistant cancer cells.

Keywords: chemoresistance, Hedgehog signaling, cyclopamine, paclitaxel, cancer stem cell
\end{abstract}

\section{Introduction}

Cyclopamine blocks Hedgehog signaling by antagonizing Smo function, which leads to apoptotic cell deaths. ${ }^{1-5}$ The application of cyclopamine causes very few adverse effects in animals, and therefore demonstrates its usefulness in clinical applications. In recent years, cyclopamine has been used effectively in treatments for multiple types of cancers, both in vitro and in vivo, such as prostate cancer and pancreas cancer. ${ }^{6-10}$ Hedgehog signaling is also important for breast cancer cells, ${ }^{11-13}$ contributing to tumor stem cell maintenance and recurrence. ${ }^{14-16} \mathrm{Here}$, we describe the use of cyclopamine to antagonize the growth and chemoresistance of breast cancer cells. The results suggest cyclopamine as a prospective conjugate in clinical therapies.

\section{Materials and methods Ethics statement}

This study was approved by the Animal Research Committee of Zhejiang XiaoShan Hospital (ZJXS2009-1073SJ).

\section{Cell culture}

MDA-MB-231 human breast cancer cells were purchased from Shengsheng Logistics (Shanghai, People's Republic of China) and maintained in Roswell Park Memorial Institute 1640 medium (Life Technologies, Carlsbad, CA, USA). Paclitaxel (Life Technologies) at $50 \mu \mathrm{M}$ was chosen as the chemotherapeutic drug, as previously described, to induce cell apoptosis. ${ }^{2,5}$ Cyclopamine at $20 \mu \mathrm{M}$ was included to examine the effects of conjugated treatments.

\section{Cell viability and apoptosis}

Cell viability was examined with an MTT (3-[4,5-dimethylthiazol-2-yl]-2,5-diphenyltetrazolium bromide) assay. The MTT assay was done with an MTT kit (EMD Millipore, 
Billerica, MA, USA), following the brochure carefully. Finally, each experiment was repeated at least three times.

The apoptotic cells were detected by a caspase- 3 activity kit (Merck, Darmstadt, Germany) and a TUNEL (terminal deoxynucleotidyl transferase deoxyuridine triphosphate nickend labeling) kit (Roche, Basel, Switzerland). The staining was performed as described in the kit. Then, the cells were counted for ten random sites at $40 \times$ magnification after staining. For confirmation of the results, DAPI (4',6-diamidino-2phenylindole; $15 \mu \mathrm{g} / \mathrm{mL}$, Sigma-Aldrich, St Louis, MO, USA) was occasionally employed for nuclei staining.

\section{Xenograft}

Sixty nude mice were injected with $2 \times 10^{6}$ cancer cells into the flank for tumor establishment for 3 weeks. Then, the mice were subdivided into three groups: control group with saline injection (every 3 days), paclitaxel (20 mg/kg/day)-treated (every 3 days), and paclitaxel ( $20 \mathrm{mg} / \mathrm{kg} /$ day) plus cyclopamine ( $25 \mathrm{mg} / \mathrm{kg} /$ day)-treated (every 3 days). The mice were killed 6 weeks and 9 weeks after the start of cancer cell transplantation for tumor harvesting. The size of the tumors was measured. Then, the tissue was fixed in $4 \%$ paraformaldehyde for 48 hours before being processed for paraffin embedding. Then, $5 \mu \mathrm{m}$ sections were prepared for TUNEL staining, and the number of apoptotic cells within the tumor was determined by positive cells/hematoxylin and eosin-stained cells.

\section{Statistics}

The data are presented as means \pm standard deviation and were analyzed with SPSS 13.0 (IBM Corporation, Armonk, NY, USA) software. The group data were compared with analysis of variance and paired $t$-tests. $P<0.05$ was determined as statistically significant.

\section{Results \\ Cyclopamine-enhanced paclitaxel-induced cell death}

We found at both the 24-hour and 48-hour time points that the addition of cyclopamine had further enhanced paclitaxel-induced cell death, reflected by both decreased percentage of viable cells and increased percentage of apoptotic cells $(P<0.05$; Table 1 and Figure 1$)$.

\section{Cyclopamine-paclitaxel combined treatment decreased tumor growth in xenograft}

We further found that in xenograft-transplanted mice, the administration of paclitaxel reduced tumor growth and enhanced cell apoptosis significantly. Interestingly, the combined administration of cyclopamine promoted the observed antitumor effect $(P<0.05$; Table 2 and Figure 2$)$.

\section{Discussion}

Hedgehog signaling is important for breast cancer cells, contributing to tumor stem cell maintenance and recurrence in multiple models. ${ }^{11-13,15,17}$ It has been found that tumor stem cells are partly responsible for the chemoresistance of tumor cells in response to chemotherapy, which is maintained by Hedgehog-signaling pathways. ${ }^{4,18-22}$ Therefore, the antagonism of Hedgehog signaling might sensitize tumor cells to chemotherapy and reduce recurrence after surgical removal. This could be the same for breast cancer, given the fact that Hedgehog signaling has been well recognized in anti-breast cancer efforts. ${ }^{14,18,23,24}$ In addition, tumor stem cells have been suggested to promote breast cancer development and recurrence. ${ }^{11,18,19,25}$

The present study examined the chemoresistance of a common chemotherapy drug - paclitaxel. Paclitaxel as a mitotic inhibitor targets tubulin, and has been employed in different types of cancers, including breast cancer. ${ }^{7,26}$ However, the chemoresistance represents a difficulty in clinical management of single-drug chemotherapy. Here, we found that the single administration of paclitaxel could reduce tumor cell survival and growth, both in vitro and in vivo, confirming previous reports. However, we showed that the combined use of cyclopamine, which blocks Hedgehog signaling, can further induce tumor cell apoptosis. This is possibly due to the loss of tumor stem cell maintenance. In future studies, it will be interesting

Table I Cyclopamine enhances paclitaxel-induced cell death

\begin{tabular}{|c|c|c|c|c|c|c|}
\hline & \multicolumn{3}{|l|}{24 hours } & \multicolumn{3}{|l|}{48 hours } \\
\hline & Control & Paclitaxel & +Cyclopamine & Control & Paclitaxel & +Cyclopamine \\
\hline Viable cells & $99.4 \% \pm 0.1 \%$ & $47.0 \% \pm 9.4 \% *$ & $20.1 \% \pm 7.3 \% \#$ & $98.7 \% \pm 0.09 \%$ & $35.6 \% \pm 2.8 \% *$ & $16.4 \% \pm 10.2 \% \#$ \\
\hline Number of repeated experiments & 3 & 6 & 6 & 3 & 6 & 6 \\
\hline Apoptotic cells & $0.2 \% \pm 0.03 \%$ & $42.1 \% \pm 7.7 \% *$ & $71.9 \% \pm 6.4 \% \#$ & $0.6 \% \pm 0.07 \%$ & $51.8 \% \pm 6.9 \% *$ & $74.2 \% \pm 9.3 \% \#$ \\
\hline Number of repeated experiments & 5 & 8 & 8 & 5 & 6 & 6 \\
\hline
\end{tabular}

Notes: $* P<0.05$ compared to control group; ${ }^{P}<0.05$ compared to paclitaxel-treated group. 


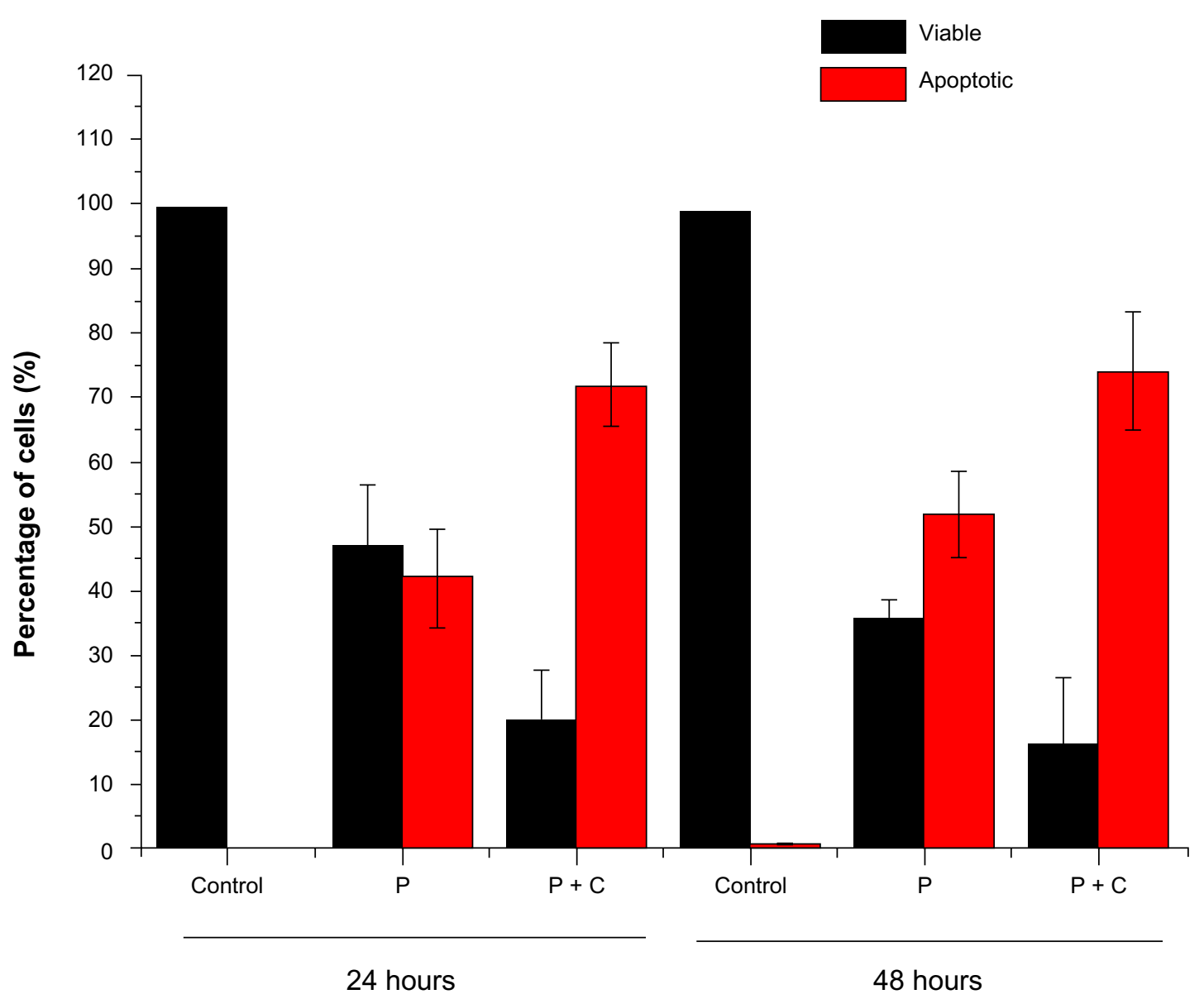

Figure I Cyclopamine-enhanced paclitaxel-induced cell death. Cyclopamine further enhances the cell apoptosis (red) and reduce the viable cells (black) at both the 24-hour and 48-hour time points.

Abbreviations: P, paclitaxel; C, cyclopamine.

to isolate these chemotherapy-resistant cells specifically for pharmacological and signaling pathway dissections. It should be noted that cyclopamine might also activate the Smo signaling pathway, and therefore partly contribute to the increased apoptosis of breast cancer cells. This requires further investigation to dissect downstream-signaling cascades.

Cyclopamine has been employed in different types of diseases, with proven use of safety. ${ }^{27,28}$ In the present study, we did not observe any adverse effects after 6 weeks of cyclopamine administration (nor in important organs by histological examination; data not shown). The combined use of cyclopamine with other chemotherapy drugs, however, should still be evaluated for any potential harm.

In conclusion, this study firstly demonstrated that combined use of cyclopamine might act as the chemoresistance remover in paclitaxel administration for breast cancer. In pancreas cancer cells, the combination was found to be unique compared to the use of other combinations. ${ }^{26}$ Whether this is the case for breast cancer is yet to be investigated. If so, this might further emphasize the importance of Hedgehog signaling and cancer stem cells in breast cancer chemoresistance to paclitaxel.

Table 2 Cyclopamine combined treatment decreases tumor growth in vivo

\begin{tabular}{|c|c|c|c|c|c|c|}
\hline & \multicolumn{3}{|l|}{6 weeks } & \multicolumn{3}{|l|}{9 weeks } \\
\hline & Control & Paclitaxel & +Cyclopamine & Control & Paclitaxel & +Cyclopamine \\
\hline Tumor size $\left(\mathrm{mm}^{3}\right)$ & $\mathrm{I}, 792 \pm 243$ & $1,329 \pm 289 *$ & $1,121 \pm 163^{\#}$ & $2,260 \pm 403$ & $1,547 \pm 274^{*}$ & $1,196 \pm 209^{\#}$ \\
\hline Number of animals & 10 & 10 & 10 & 10 & 10 & 10 \\
\hline Apoptotic cells & $1.0 \% \pm 0.2 \%$ & $29.3 \% \pm 4.7 \% *$ & $56.7 \% \pm 5.4 \%^{\#}$ & $0.8 \% \pm 0.2 \%$ & $32.4 \% \pm 3.3 \% *$ & $67.9 \% \pm 8.5 \%^{\#}$ \\
\hline Number of animals & 6 & 6 & 6 & 6 & 6 & 6 \\
\hline
\end{tabular}

Notes: $* P<0.05$ compared to control group; ${ }^{*} P<0.05$ compared to paclitaxel-treated group. 


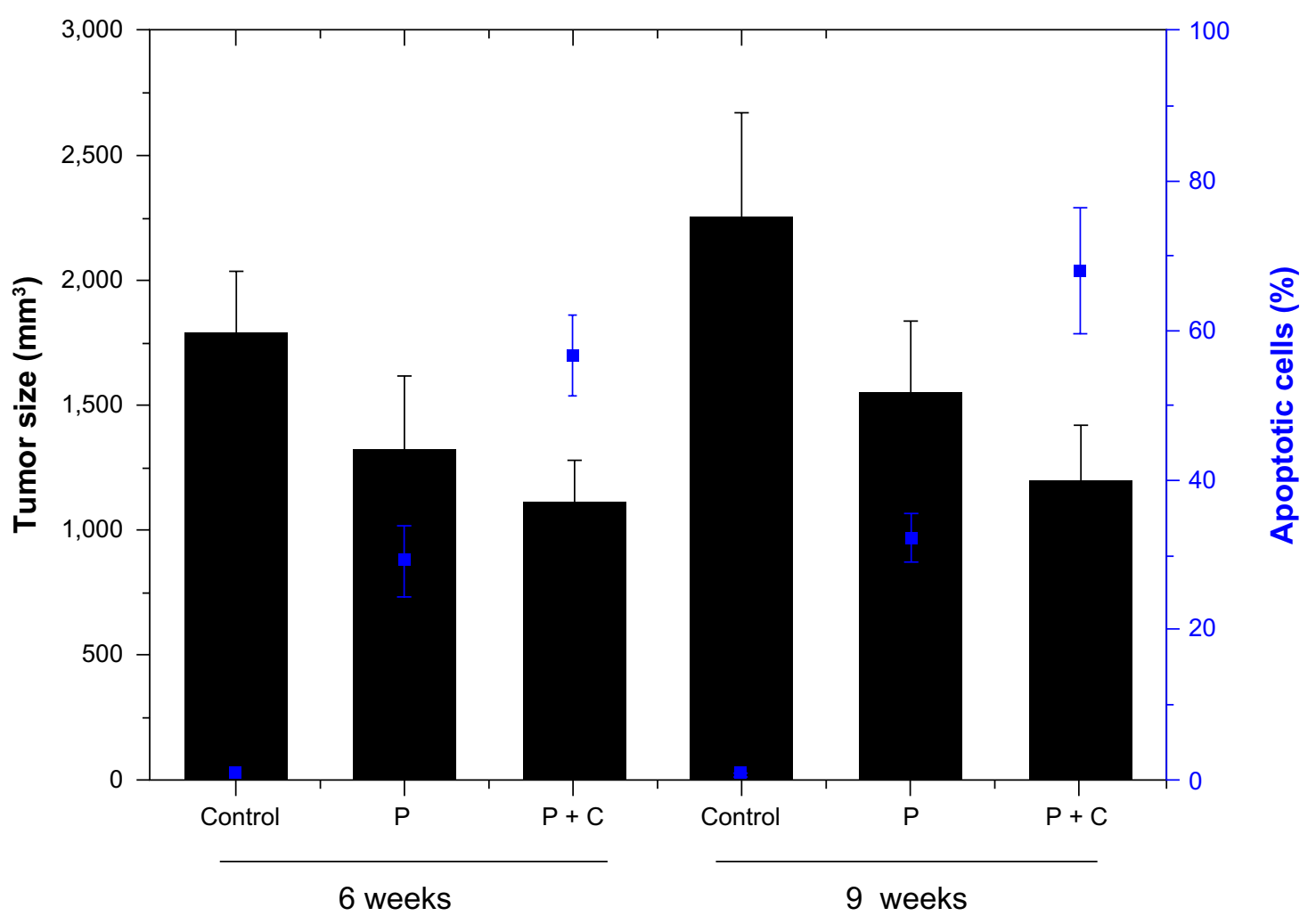

Figure 2 Cyclopamine-combined treatment decreased tumor growth in vivo. Cyclopamine further reduced the tumor size (black) and increased the cancer cell-apoptosis rate (blue), at both the 6-week and 9-week time points.

Abbreviations: $\mathrm{P}$, paclitaxel; C, cyclopamine.

\section{Author contributions}

FC, JZ, CC, PS and JS designed the study; FC, JZ, CC, SX, XC and PS performed the study; FC, JZ, CC, SX, PS and JS analyzed the data; JS provided the funding for the study; FC, SX and JS wrote the draft of the paper; all authors have drafted, revised, and approved the final version of this manuscript.

\section{Disclosure}

The authors report no conflicts of interest in this work.

\section{References}

1. Eimer S, Dugay F, Airiau K, et al. Cyclopamine cooperates with EGFR inhibition to deplete stem-like cancer cells in glioblastoma-derived spheroid cultures. Neuro Oncol. 2012;14:1441-1451.

2. Pratap A, Singh S, Mundra V, et al. Attenuation of early liver fibrosis by pharmacological inhibition of smoothened receptor signaling. J Drug Target. 2012;20:770-782.

3. Chitkara D, Singh S, Kumar V, et al. Micellar delivery of cyclopamine and gefitinib for treating pancreatic cancer. Mol Pharm. Epub July 23, 2012.

4. Lin TL, Matsui W. Hedgehog pathway as a drug target: Smoothened inhibitors in development. Onco Targets Ther. 2012;5:47-58.

5. Fan Q, Gu D, He M, et al. Tumor shrinkage by cyclopamine tartrate through inhibiting hedgehog signaling. Chin J Cancer. 2011;30: 472-481.

6. Ibuki N, Ghaffari M, Pandey M, et al. TAK-441, a novel investigational smoothened antagonist, delays castration-resistant progression in prostate cancer by disrupting paracrine hedgehog signaling. Int $J$ Cancer. 2013;133:1955-1966.
7. Singh S, Chitkara D, Mehrazin R, Behrman SW, Wake RW, Mahato RI. Chemoresistance in prostate cancer cells is regulated by miRNAs and Hedgehog pathway. PloS One. 2012;7:e40021.

8. Zhou Y, Yang J, Kopeček J. Selective inhibitory effect of HPMA copolymer-cyclopamine conjugate on prostate cancer stem cells. Biomaterials. 2012;33:1863-1872.

9. Kelleher FC. Hedgehog signaling and therapeutics in pancreatic cancer. Carcinogenesis. 2011;32:445-451.

10. Yang Y, Tian X, Xie X, Zhuang Y, Wu W, Wang W. Expression and regulation of hedgehog signaling pathway in pancreatic cancer. Langenbecks Arch Surg. 2010;395:515-525.

11. Ahmad A. Pathways to breast cancer recurrence. ISRN Oncol. 2013;2013:290568.

12. O'Toole SA, Beith JM, Millar EK, et al. Therapeutic targets in triple negative breast cancer. J Clin Pathol. 2013;66(6):530-542.

13. Ali SA. The hedgehog pathway in breast cancer. Chin J Cancer Res. 2012;24:261-262.

14. Hui M, Cazet A, Nair R, Watkins DN, O'Toole SA, Swarbrick A. The Hedgehog signalling pathway in breast development, carcinogenesis and cancer therapy. Breast Cancer Res. 2013;15:203.

15. Gupta S, Takebe N, Lorusso P. Targeting the Hedgehog pathway in cancer. Ther Adv Med Oncol. 2010;2:237-250.

16. Curtin JC, Lorenzi MV. Drug discovery approaches to target Wnt signaling in cancer stem cells. Oncotarget. 2010;1:563-577.

17. Malhotra GK, Zhao X, Band H, Band V. Shared signaling pathways in normal and breast cancer stem cells. J Carcinog. 2011;10:38.

18. Gangopadhyay S, Nandy A, Hor P, Mukhopadhyay A. Breast cancer stem cells: a novel therapeutic target. Clin Breast Cancer. 2013;13:7-15.

19. Prud'homme GJ. Cancer stem cells and novel targets for antitumor strategies. Curr Pharm Des. 2012;18:2838-2849.

20. Lu JT, Zhao WD, He W, Wei W. Hedgehog signaling pathway mediates invasion and metastasis of hepatocellular carcinoma via ERK pathway. Acta Pharmacol Sin. 2012;33:691-700. 
21. Shi Y, Fu X, Hua Y, Han Y, Lu Y, Wang J. The side population in human lung cancer cell line NCI-H460 is enriched in stem-like cancer cells. PloS One. 2012;7:e33358.

22. Wang X, Venugopal C, Manoranjan B, et al. Sonic hedgehog regulates Bmi1 in human medulloblastoma brain tumor-initiating cells Oncogene. 2012;31:187-199.

23. Goel HL, Pursell B, Chang C, et al. GLI1 regulates a novel neuropilin-2/ alpha6beta1 integrin based autocrine pathway that contributes to breast cancer initiation. EMBO Mol Med. 2013;5:488-508.

24. Das S, Tucker JA, Khullar S, Samant RS, Shevde LA. Hedgehog signaling in tumor cells facilitates osteoblast-enhanced osteolytic metastases. PloS One. 2012;7:e34374.
25. Karamboulas C, Ailles L. Developmental signaling pathways in cancer stem cells of solid tumors. Biochim Biophys Acta. 2013;1830: 2481-2495.

26. Shafaee Z, Schmidt H, Du W, Posner M, Weichselbaum R. Cyclopamine increases the cytotoxic effects of paclitaxel and radiation but not cisplatin and gemcitabine in Hedgehog expressing pancreatic cancer cells. Cancer Chemother Pharmacol. 2006;58:765-770.

27. Heretsch P, Tzagkaroulaki L, Giannis A. Modulators of the hedgehog signaling pathway. Bioorg Med Chem. 2010;18:6613-6624.

28. Katoh Y, Katoh M. Hedgehog target genes: mechanisms of carcinogenesis induced by aberrant hedgehog signaling activation. Curr Mol Med. 2009;9:873-886.

\section{Publish your work in this journal}

OncoTargets and Therapy is an international, peer-reviewed, open access journal focusing on the pathological basis of all cancers, potential targets for therapy and treatment protocols employed to improve the management of cancer patients. The journal also focuses on the impact of management programs and new therapeutic agents and protocols on

\section{Dovepress}

patient perspectives such as quality of life, adherence and satisfaction The manuscript management system is completely online and includes a very quick and fair peer-review system, which is all easy to use. Visit http://www.dovepress.com/testimonials.php to read real quotes from published authors.

Submit your manuscript here: http://www.dovepress.com/oncotargets-and-therapy-journal 